\title{
Influence of the Boundary Forcing on the Internal Variability of a Regional Climate Model
}

\author{
Kevin Sieck, Daniela Jacob \\ Climate Service Center Germany, Helmholtz-Zentrum Geesthacht, Hamburg, Germany \\ Email: kevin.sieck@hzg.de
}

Received 3 February 2016; accepted 21 August 2016; published 24 August 2016

Copyright (C) 2016 by authors and Scientific Research Publishing Inc.

This work is licensed under the Creative Commons Attribution International License (CC BY). http://creativecommons.org/licenses/by/4.0/

(c) () Dpen Access

\section{Abstract}

The internal variability of a ten-member ensemble of the regional climate model REMO over Europe is investigated. It is shown that the annual cycle of internal variability behaves differently compared to earlier studies that focused on other regions. To gain better insight into the dependence of the internal variability on the boundary forcing variability, a circulation type classification is performed on the forcing data. It can be shown that especially in the winter season internal variability is dependent on the circulation type included in the boundary forcing, whereas in the summer season the level and pattern of internal variability is rather independent from the circulation type of the driving field. It is concluded that for Europe the internal variability of REMO in winter is governed by circulation patterns related to the North-Atlantic Oscillation, whereas in summer local processes play a bigger role.

\section{Keywords}

Regional Climate Model, Internal Variability, Boundary Forcing, Circulation Type Classification

\section{Introduction}

The sensitivity of regional climate models (RCMs) to the initial conditions of the simulation at constant external forcing has recently drawn increasing attention. This sensitivity is often referred to as the internal variability (IV) of a RCM.

Especially for parameters that are important for the hydrological cycle [1] show that IV can become as large as IV in a global climate model (GCM). Reference [2] finds that large differences between two ensembles often occur simultaneously with large IV. They conclude that the comparison between only two runs in, e.g., sensitiv- 
ity studies can be misleading due to IV.

The strength of IV in a RCM is sensitive to a number of factors. Reference [3] shows that a sufficiently big domain can enhance IV. If local processes play an important role, the IV of parameters such as precipitation, mean-sea-level pressure or near-surface temperature can grow large in a RCM [4] [5]. Also the location of the domain on the globe and nonetheless the season of the year plays a role for the strength of IV [1] [4]-[8]. Reference [7] shows that for a domain over North-America the flow regime of the external forcing governs the IV of a RCM as an additional factor. They also mention that their findings might change for different regions of the world. Reference [8] points out that the temporal evolution of IV undergoes episodes of stronger and weaker IV and that it is not a phenomenon specific to one model. In an attempt to quantify the important processes that create IV in summer [9] find that the covariance of potential temperature and diabatic heating fluctuations as well as the covariance of inter-member fluctuations along ensemble-mean gradients play an important role to create IV in a RCM.

While mostly North-America and the Arctic are regions where IV has been studied, in Europe only a few investigations took place. Here we present a long-term study on IV over a European domain and analyze the importance of lateral boundary forcing in generating IV inside the domain.

To analyze the link between the variability in the external forcing and the IV of the RCM a circulation type (CT) classification of the boundary data has been performed. CT classifications exhibit a long history in meteorology and climatology and proofed to be a useful tool to understand and interpret atmospheric processes and the link between atmospheric processes and surface climate [10]. Reference [11] demonstrates successfully how CT classifications can be applied to modeled climate information from a GCM. In a study on present and future storm events [12] shows how the change in the frequency of certain CTs is linked to a change in storminess over Europe. As a third example [13] shows that biases in daily minimum and maximum temperature in an ensemble of RCMs can partly be explained by over- and underestimations of characteristic CTs in the driving GCM data. In a recent study [14] showed the usefulness of a boundary data classification to investigate the influence of different weather regimes on IV for a South-African domain.

After introducing the experimental set-up and analysis methods in Section 2, the results from the IV analysis of mean-sea-level pressure, near-surface temperature and precipitation and the link to the external forcing by means of a CT classification will be presented in Section 3. A summary and conclusions will be given in Section 4 .

\section{Method}

In this study, the IV generated by a ten-member ensemble of the RCM REMO [15] over Europe is investigated.

\subsection{Experimental Set-Up}

REMO is run for a domain covering Europe with $0.5^{\circ}$ resolution over a period of ten years (1979-1988). As lateral boundary forcing and initial atmospheric conditions ERA-40 reanalysis data [16] has been used. For the soil initial conditions were taken from a spin up simulation that shows no trend in the deepest soil layers. The model was free to develop its own mesoscale climate, i.e., no large scale nudging has been applied inside the simulation domain (except for the sponge zone).

IV is estimated from the standard deviation of a ten-member ensemble of REMO after the approach of [3]. Here, the unbiased estimator of [7] is used with the following formulation:

$$
s_{\varphi}^{2}(i, j, k, t)=\frac{1}{M-1} \sum_{m=1}^{M}(\varphi(i, j, k, t, m)-\langle\varphi\rangle(i, j, k, t))^{2}
$$

where $\varphi(i, j, k, t, m)$ is the value of a parameter $\varphi$ (e.g., temperature or precipitation) in the three dimensional grid $(i, j, k)$ at output time $t$ for ensemble member $m$. The variable $M$ is the total number of ensemble members. The term $\langle\varphi\rangle(i, j, k, t)$ corresponds to the ensemble mean and is defined as

$$
\langle\varphi\rangle(i, j, k, t)=\frac{1}{M} \sum_{m=1}^{M} \varphi(i, j, k, t, m) .
$$

As $s_{\varphi}^{2}$ gives the inter member variance for each grid cell at each output time step $t$ (6-hourly in this study), it is useful to reduce the dimensions by spatial and temporal averages in order to gain a more comprehensive over- 
view. For the time evolution of internal variability $s_{\varphi}^{2}$ is averaged over the horizontal domain by

$$
\left\{s_{\varphi}^{2}\right\}(k, t)=\frac{1}{I \cdot J} \sum_{i=1}^{I} \sum_{j=1}^{J} s_{\varphi}^{2}(i, j, k, t)
$$

with $I$ and $J$ being the number of grid boxes in the x- and y-direction or zonal and meridional direction, respectively. Although the grid rotation is optimized for similar sized grid boxes, it is stretched identical to a regular longitude/latitude grids, thus area weights are applied. For all spatial means the sponge zone of eight grid boxes is omitted on each horizontal edge of the domain.

\subsection{Circulation Type Classification}

To investigate the influence of the variability in the boundary forcing on the internal variability of REMO, a circulation type classification of the boundary data has been performed. The domain for the circulation type classification has been extended by 30 grid boxes in the zonal and 20 grid boxes in the meridional direction at each boundary to account for influences from the flow in the vicinity of the model domain.

To perform the circulation type classification of the boundary data, the circulation type classification software of the COST Action 733 Harmonisation and Applications of Weather Type Classifications for European regions [17] in version 1.0 was used. As there are many different kinds of classification methods available, several setups with different methods were tested. It was found that the outcomes did not depend on the method which gives confidence in the robustness of the results (not shown). Here, one set up for the SANDRA classification method is presented.

The assumptions needed for SANDRA prior to the classification procedure are based on the work done in COST Action 733 and by [18]. Reference [18] could show that finding the perfect number of types a priori is not straightforward and often subjective decisions have to be made. As the focus is on the influence of the large-scale flow on internal variability, the parameters used to perform the classification are daily means of meansea-level pressure and $500 \mathrm{hPa}$-geopotential height. Tests have been performed with different parameters and parameter combinations, e.g., to include vorticity or leave out mean-sea-level pressure, but results were not very sensitive to these choices (not shown). The combination of mean-sea-level pressure and $500 \mathrm{hPa}$-geopotential height lead to the best explained cluster variance (ECV) [18] among the tested parameter combinations.

The boundary forcing data is split into the four seasons winter (December-February), spring (March-May), summer (June-August) and autumn (September-November). This is done to account for the strong seasonality in the northern hemisphere extratropics [19]. In the second step, seven circulation types are chosen for winter and summer, and nine for spring and autumn. This gives 32 circulation types in total for the entire year. It has been shown by [18] that a higher number of circulation types are required in the transition seasons spring and autumn to get a more balanced distribution in the number of assigned days per circulation type. Tests with different numbers of circulation types showed that the chosen numbers yield similar results for all seasons in terms of ECV. It should be noted that the ECV only allows to compare the quality of the classification between different parameter sets for a given number of types, but cannot determine the best number of types itself. For the number of types the present study relies on the experience from COST Action 733 and is a compromise between a good separation of types, within-type variance and number of days assigned to one type for a solid statistical analysis. The result of the classification is a time series, where for each season the daily means of the boundary data are assigned to one circulation type.

\section{Results}

\subsection{Winter}

In the circulation type classification for winter, many of the circulation types shown in Figures 1(a)-(g) can be associated with well-known European circulation types from other classification methods such as, e.g., the Großwetterlagen classification by [20]. One good example is circulation type 1 that shows a subtropical high shifted to the north-east and a low over the Barents Sea. This circulation type is similar to a Nord westlage, where the low pressure systems are traveling from Iceland over Scandinavia towards Russia. Another typical circulation type would be circulation type 6 which can be associated with a Westlage. In the case of a Westlage, the tracks of the synoptic disturbances are shifted to the south, so that they can influence central Europe. 


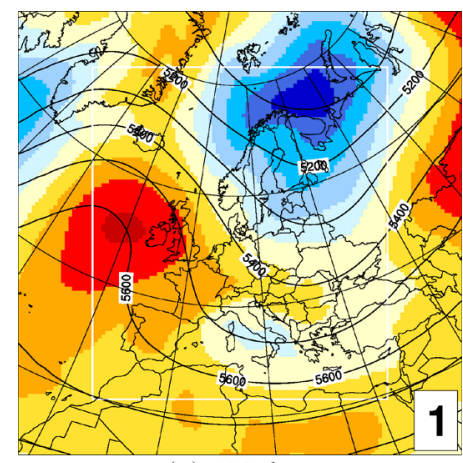

(a) 126 days

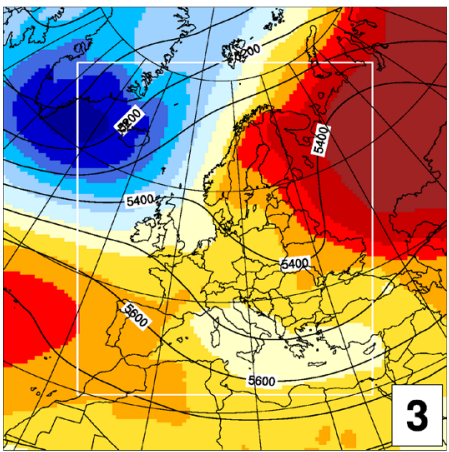

(c) 151 days

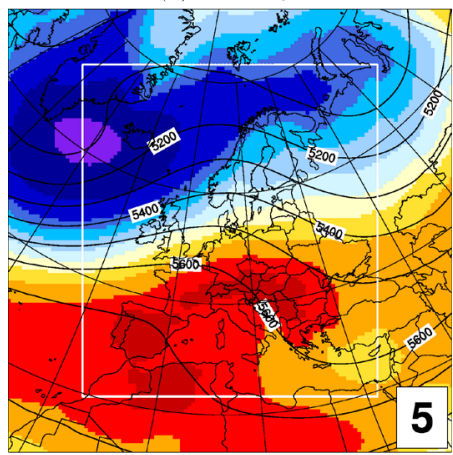

(e) 154 days

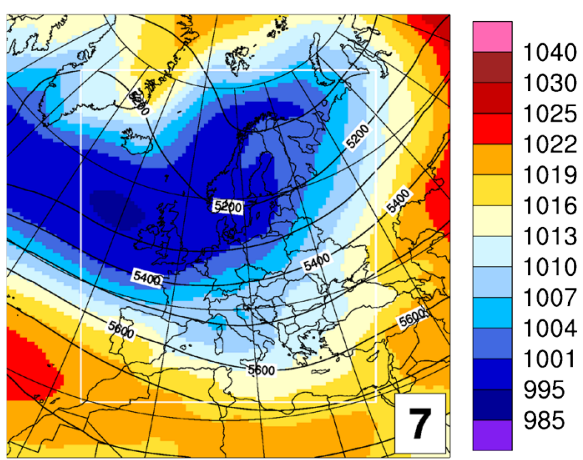

(g) 134 days

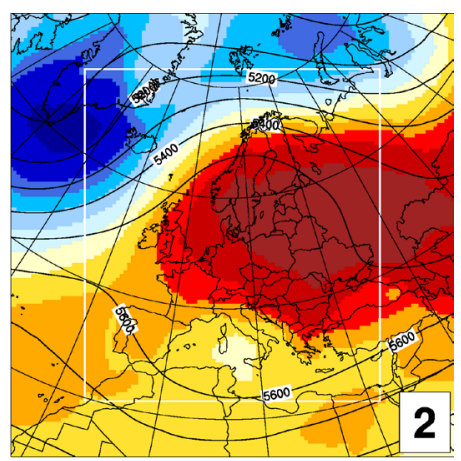

(b) 116 days

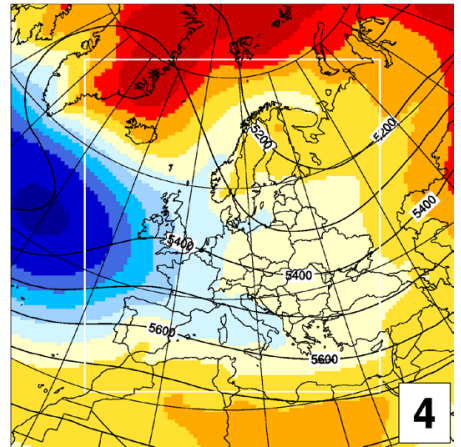

(d) 83 days

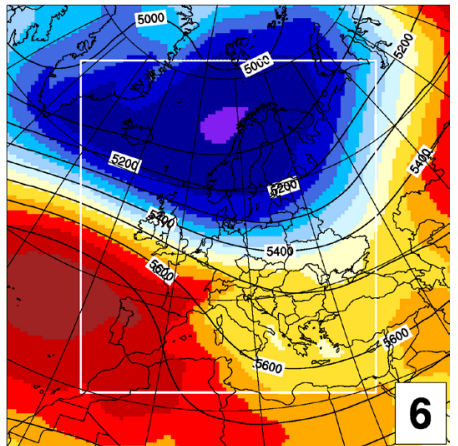

(f) 139 days

Figure 1. Winter (December-February) circulation types of the boundary data. Colored shades show the centroids (mean pattern) of mean-sea-level pressure field in $\mathrm{hPa}$. Solid lines are the centroids of the $500 \mathrm{hPa}$-geopotential height field in gpm with a $100 \mathrm{gpm}$ contour interval. The white rectangle highlights the position of the model domain. The circulation type number is given in the lower right corner of each figure. Numbers below indicate how many days in the ten year period were assigned to each circulation type. 
Figure 2 shows the median (dot) and the interquartile range (error-bars) of internal variability for mean-sealevel pressure, near-surface temperature and precipitation for each winter circulation type. It can be seen that in winter certain circulation types, such as circulation type 4 , show a higher median of internal variability than others (e.g., circulation type 6). The circulation types can be roughly categorized into three internal variability groups, with low, medium, and high internal variability. The low internal variability group, consisting of circulation type 5 and circulation type 6 , have the strongest meridional mean-sea-level pressure gradients amongst all the winter circulation types. Such situations lead to higher wind speeds and thereby stronger forcing from the boundaries inside the domain. As a consequence, the evolution of internal variability inside the domain is suppressed or quickly advected out of the domain. This is also reflected in the corresponding internal variability strengths. The mean-sea-level pressure patterns for circulation type 5 and circulation type 6 can also be related to a positive phase of the NAO that is characterized by enhanced storm activity and higher wind speeds in central Europe.

The median of mean-sea-level pressure internal variability only reaches values of about $0.4 \mathrm{hPa}$ and near-surface temperature internal variability is only about $0.4 \mathrm{~K}$. For precipitation circulation type 5 and circulation type 6 have different medians, of $0.8 \mathrm{~mm} / \mathrm{d}$ and $1.2 \mathrm{~mm} / \mathrm{d}$, respectively. The difference can be explained by the higher fraction of convective precipitation in the total precipitation in circulation type 6 compared to circulation type 5 (not shown). A higher fraction of convective precipitation leads to more variability due to the non-linear and more local processes involved.

The medium internal variability group consists of circulation type 1 through circulation type 3 and circulation type 7. For these circulation types the meridional gradients in mean-sea-level pressure are weaker than the low internal variability group. The model has more freedom to develop its own circulation and hence internal variability is stronger. The mean-sea-level pressure internal variability has median values reaching from $0.7-1.3 \mathrm{hPa}$ and median near-surface temperature internal variability of $0.81 \mathrm{~K}$. Median precipitation internal variability varies between $1.5-1.9 \mathrm{~mm} / \mathrm{d}$.

The high internal variability group is only represented by circulation type 4. Correspondingly meridional mean-sea-level pressure gradients are weak in the center of the domain. The mean-sea-level pressure pattern even shows an outflow zone in the North-West of the domain so that the predominant westerlies cannot suppress internal variability inside the domain. Circulation type 4 can also be associated with the negative phase of the NAO. Here the storms are usually forced to travel towards the Mediterranean. Central and northern Europe are dominated by dry and cold conditions. The median internal variability reaches $2.2 \mathrm{hPa}$ for mean-sea-level pressure, $1.6 \mathrm{~K}$ for near-surface temperature, and $2.5 \mathrm{~mm} / \mathrm{d}$ for precipitation.

If normalized by the maximum median, mean-sea-level pressure internal variability is almost ten times small-

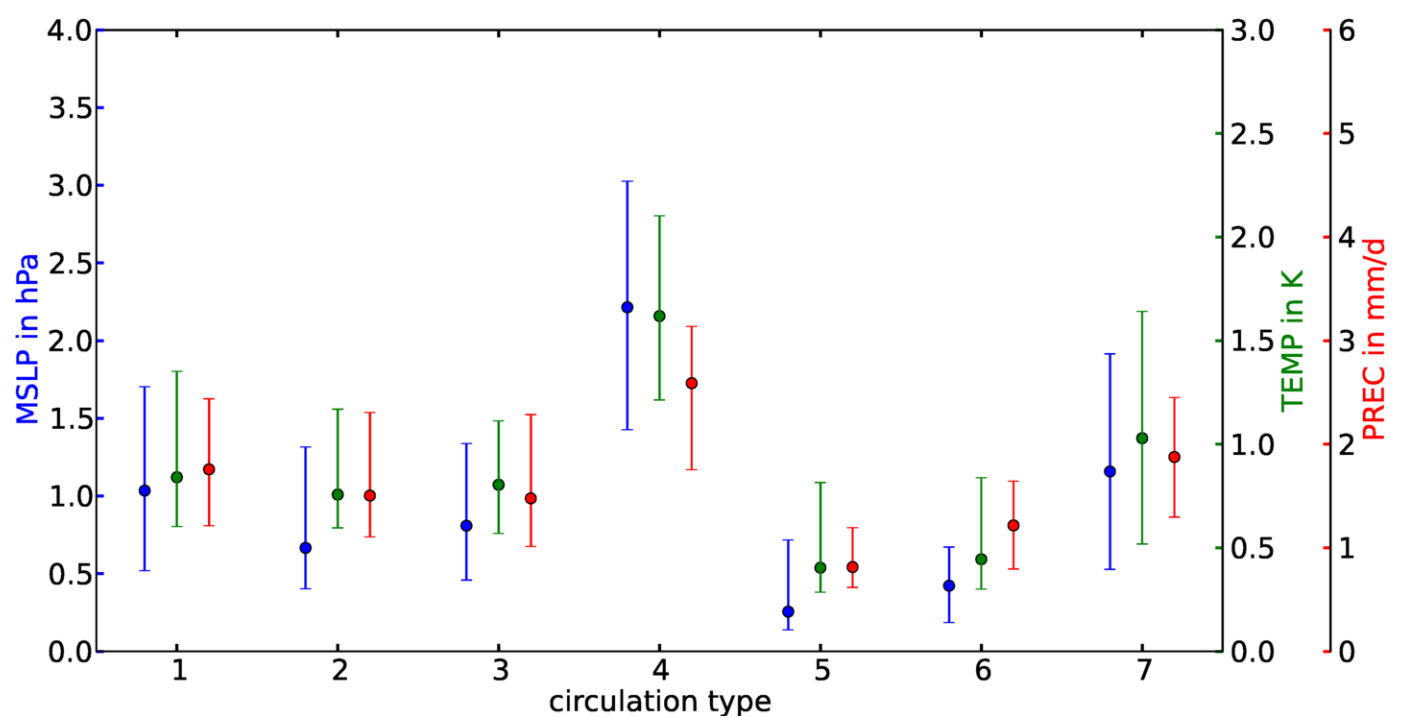

Figure 2. Level of internal variability for mean-sea-level pressure (MSLP, blue), near-surface temperature (TEMP, green), and precipitation (PREC, red) is given for each winter circulation type. Dots indicate the median internal variability and error-bars the corresponding interquartile range. 
er in the median between circulation type 5 and circulation type 4 . The difference becomes smaller with a factor four for near-surface temperature and a factor three for precipitation internal variability. This means that the internal variability of large-scale parameters such as mean-sea-level pressure are stronger affected by the the forcing field variability.

For winter most of the circulation types are quite distinct, i.e., the differences in distributions of internal variability assigned to these types are highly significant as defined by the Kruska-Wallis-Test. Hence, the flow patterns of these circulation types are linked to the internal variability in the regional climate model. Despite the fact that winter circulation types are linked to the internal variability of a regional climate model, there is still a substantial amount of variability. One reason can be attributed to the transitions between different circulation types because internal variability has a memory, as shown by [9] for example. This means that pockets of internal variability need to be advected out of the domain, or dissipated by diffusion within the domain, to lower the level of internal variability. In the opposite direction when going from a lower to a higher internal variability state, it takes some time to develop internal variability. This argument is supported by the transition probabilities between the circulation types (not shown).Winter shows a transition cascade from circulation type 1 to circulation type 4 and circulation type 7 thereafter. This means that the probability of entering circulation type 4 is highest from circulation type 1 and the highest probability of leaving circulation type 4 is moving to circulation type 7. This cascade links the circulation types with the highest levels of internal variability in winter for the investigated parameters mean-sea-level pressure, near-surface temperature and precipitation. This shows the connection between circulation type transition and internal variability for these circulation types and explains parts of the variability of internal variability within each circulation type.

As seen earlier, the mean-sea-level pressure patterns similar to negative and positive phases of the NAO have large impacts on the spatial mean internal variability. Figure 3 depicts the mean patterns for near-surface temperature internal variability of circulation type 4 and circulation type 6 . A large area centered around the Baltic Sea is subject to large internal variability in case of NAO negative like situations. Here, the mean near-surface temperature internal variability can easily reach $2.5 \mathrm{~K}$ and more. In the case of circulation type 6 (Figure 3(b)) the center of main internal variability is shifted to the north and is much weaker with only up to $1.6 \mathrm{~K}$ of mean near-surface temperature internal variability. These two patterns closely correspond to the typical tracks of storms in negative and positive phases of the NAO. The main flow in NAO negative situations is weaker and tends to be near the northern and/or southern boundaries of the domain. In NAO positive situations the flow is generally stronger and towards the center of the domain, thus suppressing internal variability in the center.

\subsection{Summer}

The summer circulation types in Figures 4(a)-(g) show a rather different picture compared to winter. All circulation types show different strengths of the sub-tropical high over the Azores with varying influences on central Europe; reflecting the different flow regime of the summer months compared to winter. The strength of internal variability is very similar for all circulation types (Figure 5), except for circulation type 19 which has lower median values for all three parameters compared to the other circulation types. Circulation type 19 has the strongest forcing from westerlies in summer (Figure 4(c)) that looks similar to a positive NAO-like pattern. Interestingly circulation type 19 resembles a positive NAO-like pattern of autumn NAO [21]. The high frequency of occurrence towards late August (not shown) shows that circulation type 19 can indeed be identified as a circulation type that marks a transition towards autumn. Nevertheless internal variability is stronger compared to similar circulation types such as circulation type 5 in winter or circulation type 14 in spring for at least meansea-level pressure and precipitation. One reason is the weaker gradient in mean-sea-level pressure, but also the higher importance of local processes in summer play a role. This means that flow patterns can only modulate the internal variability within the domain in summer. Most of the internal variability is more related to regional and local-scale processes as already suggested by [22].

The independence of the internal variability from the boundary conditions in summer can also be seen in the spatial pattern, which looks rather similar for different circulation types. To demonstrate this Figure 3 shows the mean internal variability of near-surface temperature for (c) circulation type 18 and (d) circulation type 23. Except for small differences in strength the patterns are the same. Both are also rather similar to the overall summer mean pattern (not shown). Hence, the development of internal variability in summer is governed by local processes. 


\section{Conclusions}

The circulation type classification of the lateral boundary forcing has shown that the episodic behavior of internal variability can be related to the variability of the boundary forcing as already speculated by [8]. This is especially the case for the winter season. In winter, NAO-like patterns have the strongest influence on the strength of internal variability inside the domain, with high (low) internal variability for NAO negative (positive) like circulation types. This can be explained by the strength of the westerly flow that is stronger in NAO positive compared to NAO negative phases [21]. For summer the weakest influence of circulation types on the strength of internal variability is found, which leads to the same conclusion drawn by [5] and [22] that internal variability in summer is closely related to local processes. The transition seasons spring and autumn show a mixed behavior. In both seasons circulation types with strong westerly flows show in general weaker internal variability and vice versa. This effect, however, becomes weaker for parameters that are more related to local processes like precipitation.

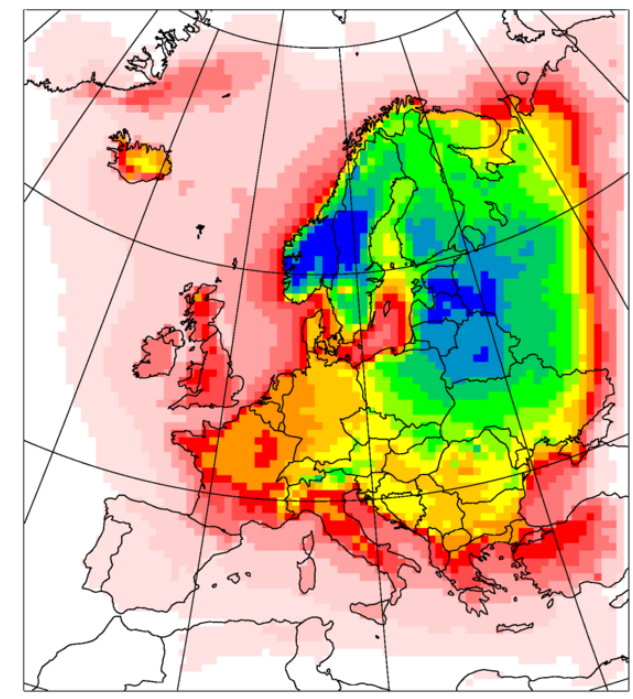

(a)

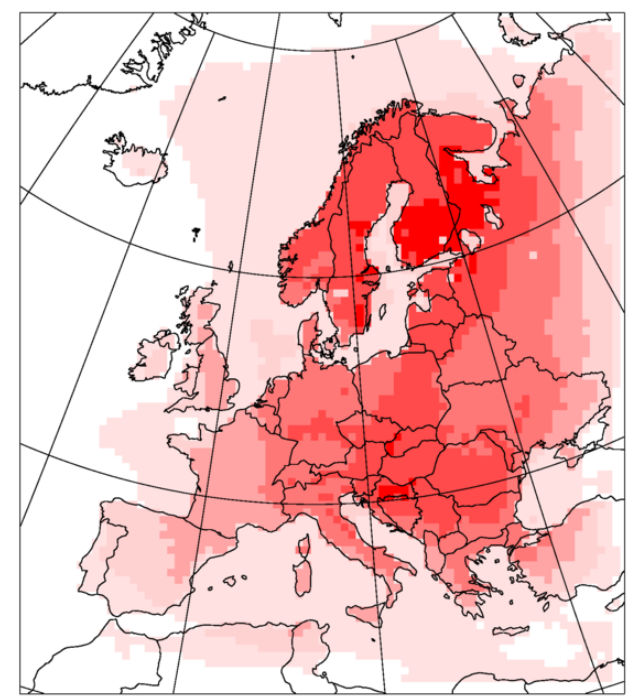

(c)
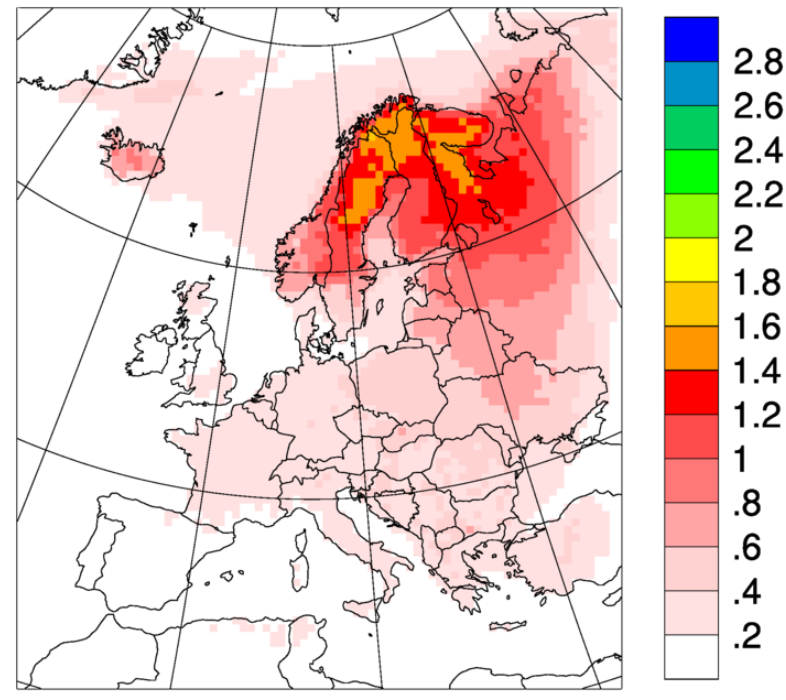

(b)
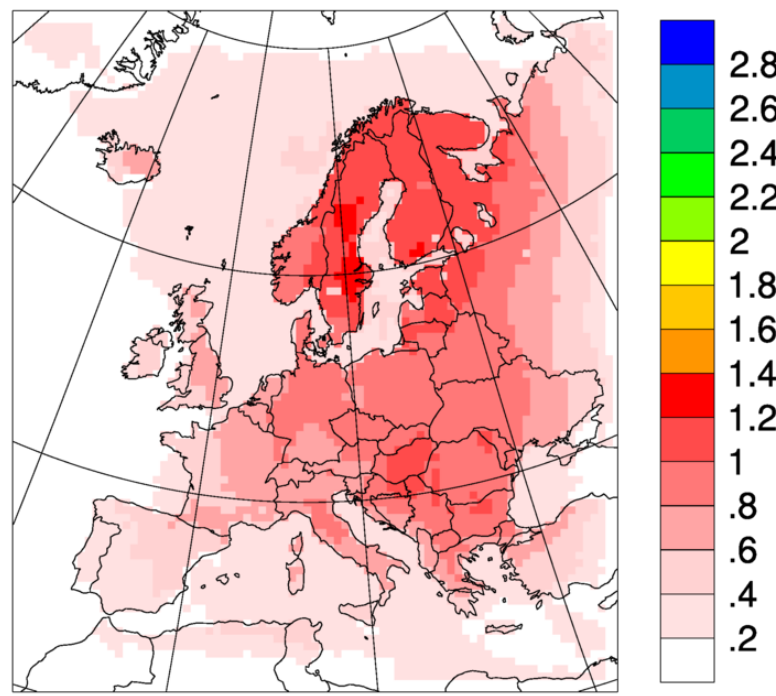

(d)

Figure 3. Mean patterns of daily mean near-surface temperature internal variability in K for winter (a) circulation type 4 and (b) circulation type 6 and summer (c) circulation type 18 and (d) circulation type 23. 


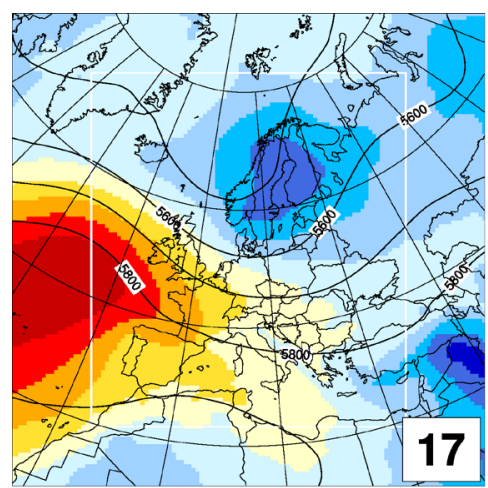

(a) 123 days

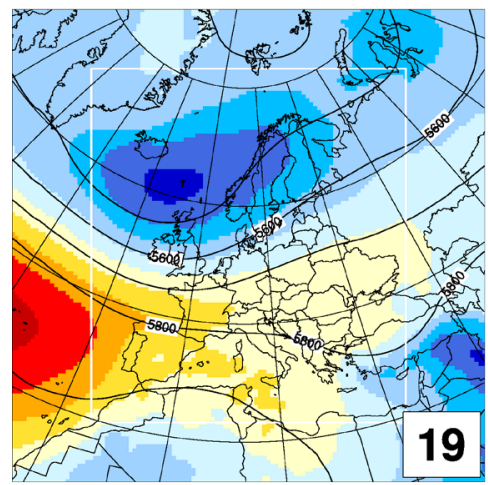

(c) 122 days

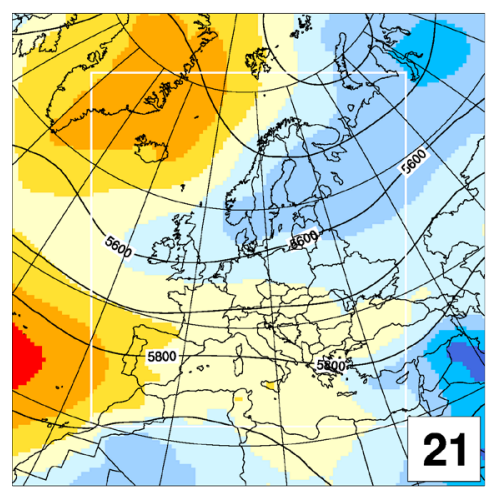

(e) 127 days

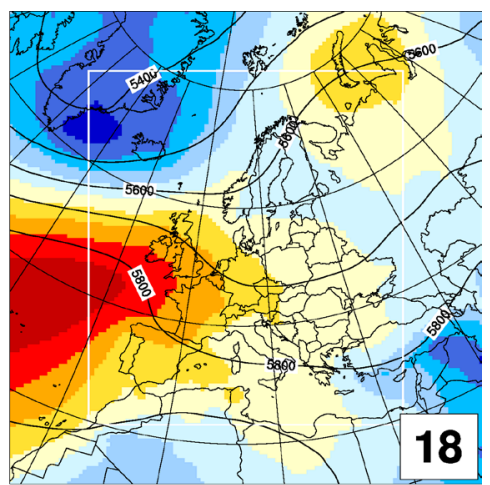

(b) 121 days

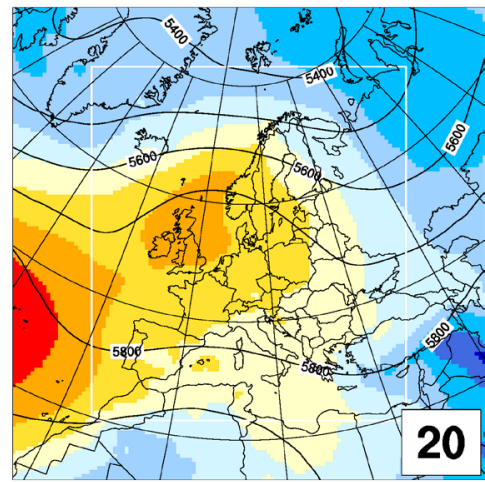

(d) 147 days

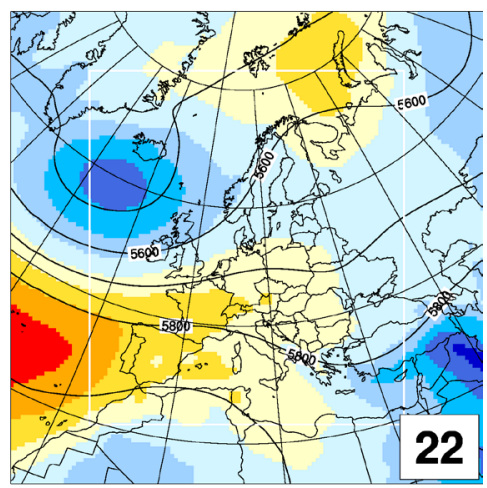

(f) 157 days

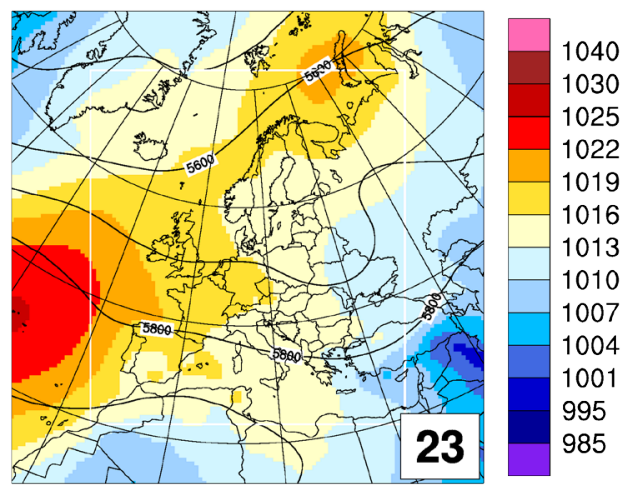

(g) 123 days

Figure 4. Same as Figure 1 but for summer circulation types. 


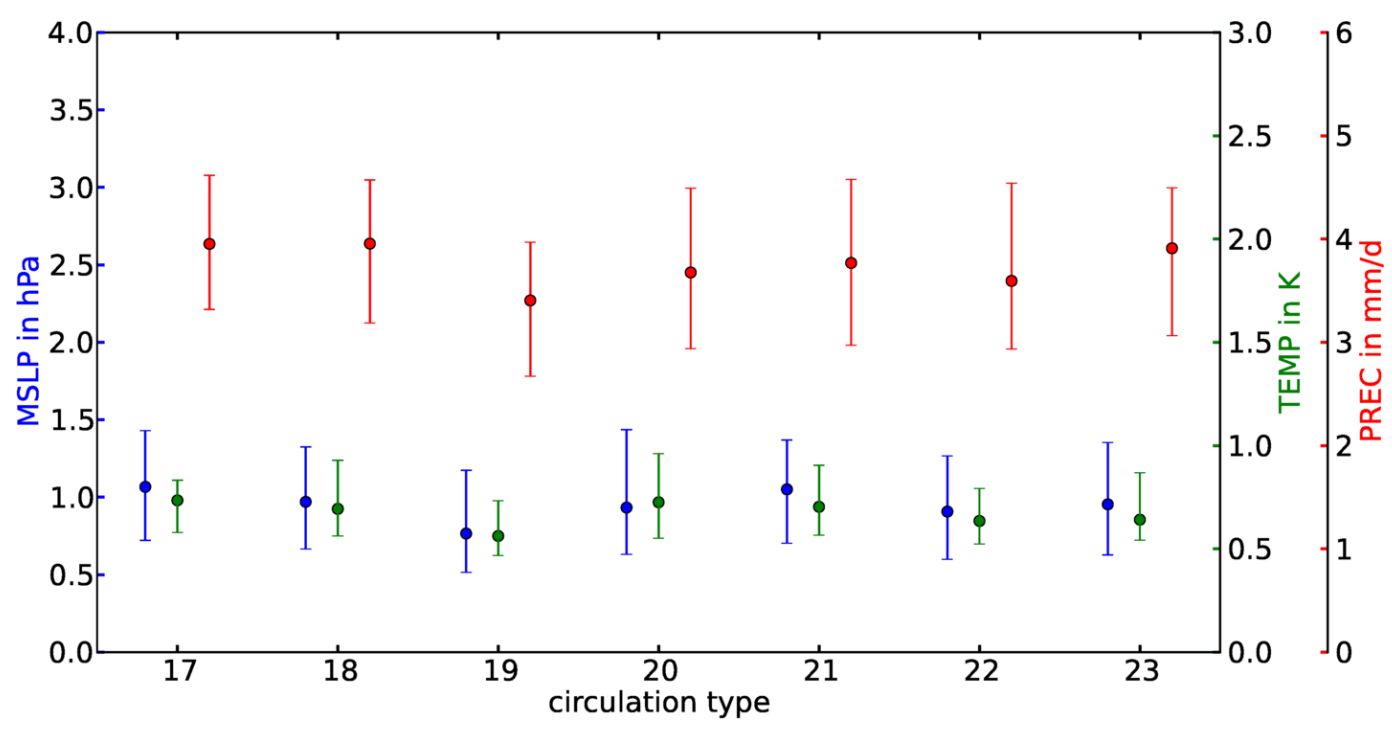

Figure 5. Same as Figure 2 but for summer circulation types.

For short range sensitivity studies with limited area models over Europe these findings can be of great value. A simple analysis of the NAO state would tell if the chosen episode could be influenced by internal variability. In case of negative NAO, this would mean that ensemble calculations might be necessary to achieve robust results.

In future studies, the link between NAO and internal variability should be investigated further. It will be most interesting to see what processes lead to the strong internal variability phases for negative NAO. The framework developed by [9] could be good starting point to analyze the processes. Furthermore, it should be investigated how big domains with high resolution are affected by internal variability.

\section{Acknowledgements}

The authors like to acknowledge the funding from the Federal Ministry of Education and Research in Germany (BMBF) through the research program "MiKlip" (FKZ 01LP1156A). The authors like to thank ECMWF for providing the ERA-40 data, the COST action 733 for providing the circulation type software, and DKRZ for providing the computing time for the simulations.

\section{References}

[1] Christensen, J.H., Raisanen, J., Iversen, T., Bjorge, D., Christensen, O.B. and Rummukainen, M. (2001) A Synthesis of Regional Climate Change Simulationsa Scandinavian Perspective. Geophysical Research Letters, 28, 1003-1006. http://dx.doi.org/10.1029/2000GL012196

[2] Weisse, R., Heyen, H. and von Storch, H. (2000) Sensitivity of a Regional Atmospheric Model to a Sea State-Dependent Roughness and the Need for Ensemble Calculations. Monthly Weather Review, 128, 3631-3642. http://dx.doi.org/10.1175/1520-0493(2000)128<3631:SOARAM>2.0.CO;2

[3] Alexandru, A., de Elia, R. and Laprise, R. (2007) Internal Variability in Regional Climate Downscaling at the Seasonal Scale. Monthly Weather Review, 135, 3221-3238. http://dx.doi.org/10.1175/MWR3456.1

[4] Giorgi, F. and Bi, X.Q. (2000) A Study of Internal Variability of a Regional Climate Model. Journal of Geophysical Research-Atmospheres, 105, 29503-29521. http://dx.doi.org/10.1029/2000JD900269

[5] Caya, D. and Biner, S. (2004) Internal Variability of RCM Simulations over an Annual Cycle. Climate Dynamics, 22, 33-46. http://dx.doi.org/10.1007/s00382-003-0360-2

[6] Rinke, A. and Dethloff, K. (2000) On the Sensitivity of a Regional Arctic Climate Model to Initial and Boundary Conditions. Climate Research, 14, 101-113. http://dx.doi.org/10.3354/cr014101

[7] Lucas-Picher, P., Caya, D., de Elia, R. and Laprise, R. (2008) Investigation of Regional Climate Models’ Internal Variability with a Ten-Member Ensemble of 10-Year Simulations over a Large Domain. Climate Dynamics, 31, 927-940. http://dx.doi.org/10.1007/s00382-008-0384-8 
[8] Laprise, R., Kornic, D., Rapaic, M., Separovic, L., Leduc, M., Nikiema, O., di Luca, A., Diaconescu, E., Alexandru, A., Lucas-Picher, P., de Elia, R., Caya, D. and Biner, S. (2012) Considerations of Domain Size and Large-Scale Driving for Nested Regional Climate Models: Impact on Internal Variability and Ability at Developing Small-Scale Details. Climate Change, Springer-Verlag, Wien, 244. http://dx.doi.org/10.1007/978-3-7091-0973-1_14

[9] Nikiema, O. and Laprise, R. (2011) Diagnostic Budget Study of the Internal Variability in Ensemble Simulations of the Canadian RCM. Climate Dynamics, 36, 2313-2337. http://dx.doi.org/10.1007/s00382-010-0834-y

[10] Huth, R., Beck, R., Philipp, A., Demuzere, M., Ustrnul, Z., Cahynova, M., Kysely, J. and Tveito, O.E. (2008) Classifications of Atmospheric Circulation Patterns Recent Advances and Applications. Trends and Directions in Climate Research, 1146.

[11] Demuzere, M., Werner, M., van Lipzig, N.P.M. and Roeckner, E. (2009) An Analysis of Present and Future Echam5 Pressure Fields Using a Classification of Circulation Patterns. International Journal of Climatology, 29, 1796-1810. http://dx.doi.org/10.1002/joc.1821

[12] Donat, M.G., Leckebusch, G.C., Pinto, J.G. and Ulbrich, U. (2010) European Storminess and Associated Circulation Weather Types: Future Changes Deduced from a Multi-Model Ensemble of GCM Simulations. Climate Research, 42 , 27-43. http://dx.doi.org/10.3354/cr00853

[13] Plavcova, E. and Kysely, J. (2011) Evaluation of Daily Temperatures in Central Europe and Their Links to Large-Scale Circulation in an Ensemble of Regional Climate Models. Tellus Series A-Dynamic Meteorology and Oceanography, 63,763-781. http://dx.doi.org/10.1111/j.1600-0870.2011.00514.X

[14] Cretat, J., Macron, C., Pohl, B. and Richard, Y. (2011) Quantifying Internal Variability in a Regional Climate Model: A Case Study for Southern Africa. Climate Dynamics, 37, 1335-1356. http://dx.doi.org/10.1007/s00382-011-1021-5

[15] Jacob, D., Van den Hurk, B.J.J.M., Andrae, U., Elgered, G., Fortelius, C., Graham, L.P., Jackson, S.D., Karstens, U., Kopken, C., Lindau, R., Podzun, R., Rockel, B., Rubel, F., Sass, B.H., Smith, R.N.B. and Yang, X. (2001) A Comprehensive Model Inter-Comparison Study Investigating the Water Budget during the Baltex-Pidcap Period. Meteorology and Atmospheric Physics, 77, 19-43. http://dx.doi.org/10.1007/s007030170015

[16] Uppala, S.M., et al. (2005) The Era-40 Re-Analysis. Quarterly Journal of the Royal Meteorological Society, 131, 2961-3012. http://dx.doi.org/10.1256/qj.04.176

[17] Philipp, A., Beck, C., Huth, R. and Jacobeit, J. (2014) Development and Comparison of Circulation Type Classifications Using the Cost 733 Dataset and Software. International Journal of Climatology.

[18] Philipp, A., Della-Marta, P.M., Jacobeit, J., Fereday, D.R., Jones, P.D., Moberg, A. and Wanner, H. (2007) Long-Term Variability of Daily North Atlantic-European Pressure Patterns since 1850 Classified by Simulated Annealing Clustering. Journal of Climate, 20, 4065-4095. http://dx.doi.org/10.1175/JCLI4175.1

[19] Wallace, J.M., Zhang, Y. and Lau, K.H. (1993) Structure and Seasonality of Interannual and Interdecadal Variability of the Geopotential Height and Temperature-Fields in the Northern-Hemisphere Troposphere. Journal of Climate, 6, 2063-2082. http://dx.doi.org/10.1175/1520-0442(1993)006<2063:sasoia>2.0.co;2

[20] Gerstengarbe, F.W.and Werner, P.C. (2005) Katalog der großwetterlageneuropas (1881-2004) nach Paul Hess und Helmut Brezowsky, 6, verbesserte und ergänzte Auflage. PIK Reports 100, Potsdam Institute for Climate Impact Research (PIK).

[21] Hurrell, J.W., Kushnir, Y., Ottersen, G. and Visbeck, M. (2003) The North Atlantic Oscillation: Climatic Significance and Environmental Impact. Vol. 134, AGU, Washington DC. http://dx.doi.org/10.1029/GM134

[22] Christensen, O.B., Gaertner, M.A., Prego, J.A. and Polcher, J. (2001) Internal Variability of Regional Climate Models. Climate Dynamics, 17, 875-887. http://dx.doi.org/10.1007/s003820100154 


\section{Submit or recommend next manuscript to SCIRP and we will provide best service for you:}

Accepting pre-submission inquiries through Email, Facebook, LinkedIn, Twitter, etc.

A wide selection of journals (inclusive of 9 subjects, more than 200 journals)

Providing 24-hour high-quality service

User-friendly online submission system

Fair and swift peer-review system

Efficient typesetting and proofreading procedure

Display of the result of downloads and visits, as well as the number of cited articles

Maximum dissemination of your research work

Submit your manuscript at: http://papersubmission.scirp.org/ 